1

2

3

4

5

6

9

\title{
Demonstration of resistance to satyrization behavior in Aedes aegypti (Linnaeus) from La
}

\section{Réunion island}

Hamidou Maïga ${ }^{1,2^{*}}$, Jérémie R. L. Gilles ${ }^{1}$, Rosemary Susan Lees ${ }^{3}$, Hanano Yamada $^{1}$, Jérémy Bouyer ${ }^{1 *}$

${ }^{1}$ Insect Pest Control Laboratory, Joint FAO/IAEA Division of Nuclear Techniques in Food and Agriculture, International Atomic Energy Agency, Vienna, Austria,

${ }^{2}$ Institut de Recherche en Sciences de la Santé/Direction Régionale de l'Ouest, Bobo-Dioulasso, Burkina Faso,

\section{${ }^{3}$ Vector Biology Department, Liverpool School of Tropical Medicine, Pembroke Place, Liverpool, L3} 5QA, United Kingdom.

HM*: Hamidou Maiga : h.maiga @iaea.org; maigahamid@yahoo.fr

JRLG: Jérémie R.L. Gilles jeremie.gilles@gmail.com

RSL: Rosemary Susan Lees rosemarysusanlees@gmail.com

HY: Hanano Yamada h.yamada@iaea.org

JB*: Jérémy Bouyer j.bouyer@iaea.org

*Corresponding author

Short title: Resistance to satyrization behaviour in Aedes aegypti

\begin{abstract}
Aedes aegypti and Aedes albopictus are competent vectors of arboviruses such as dengue and chikungunya viruses which co-exist in some areas including La Réunion island. A kind of reproductive interference called satyrization has been described in sympatric species where a dominant species tends to control the spread of the other species. Here, we investigated satyrization in laboratory experiments to provide insights on the potential impact on Ae. aegypti of a control campaign including
\end{abstract}


a sterile insect technique component against Ae. albopictus. Different mating crosses were used to test sympatric, conspecific-interspecific and allopatric effects of irradiated and non-irradiated male Ae. albopictus on female Ae. aegypti, including in a situation of skewed male ratio. Our results suggest that there was only a low level of satyrization between sympatric populations of Ae. aegypti and Ae. albopictus colonised from La Réunion island. A male Ae. albopictus to female Ae. aegypti ratio of 3:1 did not increase the level of satyrization. Female Ae. aegypti previously mated to male Ae. albopictus were not prevented from being inseminated by conspecific male Ae. aegypti. A satyrization effect was not seen between allopatric Ae. albopictus and Ae. aegypti strains from La Réunion Island either. The tested Ae. aegypti strain from La Réunion island has therefore developed full resistance to satyrization and so releasing sterile male Ae. albopictus may not suppress Ae. aegypti populations if an overflooding of irradiated male Ae. albopictus leads to similar results. The management strategy of two competent species in a sympatric area is discussed.

Key words: Aedes albopictus, satyrization, sterile insect technique, mating 


\section{INTRODUCTION}

Aedes albopictus (Skuse), the Asian tiger mosquito, has been invasive in many parts of the world since the 80s (Benedict et al. 2007). Aedes aegypti (Linnaeus), also called the yellow fever mosquito and originating from Africa, is a highly invasive, medically important mosquito species which has received a considerable increase in attention after being linked to the Zika outbreak in Brazil in 2015 (de Araújo et al. 2016). Both species transmit several arboviral diseases including dengue, chikungunya, yellow fever and Zika (Levy Blitchtein et al. 2016). Dengue alone is estimated to infect 390 million people per year, causing 96 million cases with clinical manifestations (Bhatt et al. 2013). Aedes albopictus (Skuse) and Ae. aegypti are the most important vectors of the epidemic forms of dengue and chikungunya viruses to humans (Kyle \& Harris, 2008; Paupy et al. 2010). Aedes albopictus is also responsible for the major chikungunya outbreak in the islands of the South-West Indian Ocean, including La Réunion island (an overseas department of France) between 2005 and 2007 (Delatte et al. 2008) and for the more recent dengue outbreaks according to the local health authority (Agence Régionale de Santé Océan Indien) and the regional office of Santé publique France on La Réunion island (WHO 2019).

The heavy reliance on insecticides to control adult Aedes mosquitoes, especially during disease outbreaks, has led to the emergence of widespread resistance to these chemicals, making traditional control strategies insufficient to achieve adequate reduction of vector populations. The use of insecticides is also inefficient against these container-breeding mosquito species with disseminated larval habitats. Therefore, complementary vector control methods are needed to enhance existing efforts (WHO 2017). Amongst those being advocated is the sterile insect technique (SIT), a speciesspecific and environmentally-friendly pest population control method which relies on maintaining a continuous production and repeated release of over-flooding numbers of sterile males (Knipling, 1959) that can outcompete their wild counterparts within the target area (Dyck et al. 2005) and induce sterility in wild females. A feasibility assessment of an area-wide integrated pest management (AWIPM) program with an SIT component is ongoing on La Réunion island, where Ae. albopictus cooccurs with Ae. aegypti. The first releases of sterile male Ae. albopictus mosquitoes to study their behavior in urban areas were recently authorized by a prefectural order to the Institute for Research for 
Development (IRD) (Arrêté No 2019-2213/SG/DRECV). To successfully and cost-effectively apply the SIT in an area, it is recommended to target one species at a time (Dyck et al. 2005; Alphey et al. 2010). For example, where Ae. aegypti and Ae. albopictus are sympatric and are both competent vectors of human viruses, one would consider the best approach to guarantee successful suppression or elimination of both species. The best scenario would be the release of one species which was able to also readily mate with and induce sterility in the other species (Honma et al. 2019). This phenomenon is known as reproductive interference or satyrization, in which males of one species mate with and sterilize females of another species, and in this way contribute to its displacement from the shared area (Ribeiro 1988). Reproductive interference has been described in sympatric species including ticks in Mozambique (Bournez et al. 2015).

Satyrization was proposed as a possible mechanism for the displacement of Ae. aegypti by Ae. albopictus in Florida in the late 80s (Nasci et al. 1989; Tripet et al. 2011). Satyrisation and other factors such as larval competition, climate and socioeconomic factors have influenced the distribution dynamics of the two species worldwide. A rapid decline in Ae. aegypti in the south eastern USA and Bermuda, for example, was associated with the invasions of Ae. albopictus (Nasci et al. 1989, Lounibos, 2002, Kaplan et al. 2010). The same mechanism was suggested to explain the spread of invasive Ae. albopictus in Athens, Greece and the reduction in distribution of the native Ae. cretinus (Giatropoulos et al. 2015). Displacement of Ae. albopictus by Ae. aegypti also occurred in some tropical cities in Asia including Bangkok, Kuala Lumpur, Manilla and southern Taiwan and more recently in the Colombian port of Leticia (reviewed in Lounibos and Juliano, 2018). However, it is suggested that resistance to satyrization may evolve more rapidly in female Ae. aegypti populations sympatric to Ae. albopictus than in females from allopatric populations (Bargielowski et al. 2013; Lounibos et al. 2016). Bagny et al. (2009) reported a progressive decrease in Ae. aegypti distribution on La Réunion island since the 1900s where it was mainly found in rock holes with Ae. albopictus in the ravines located on the driest west coast of the island and was absent from artificial containers. The same study suggested that the dwindling Ae. aegypti densities observed during the 1950s was due to ecological factors including a competitive interaction between Ae. aegypti and Ae. albopictus 

the competitive interaction between La Réunion island strains has not yet been investigated. With both Ae. aegypti and Ae. albopictus being competent vectors of dengue and several other arboviruses including chikungunya and Zika viruses (Lounibos, 2002; Paupy et al. 2009; ChouinCarneiro et al. 2016), it is important to investigate whether or not the release of irradiated $A e$. albopictus males would affect Ae. aegypti populations (Conseil scientifique de l'Agence française pour la biodiversité 2018), in the framework of the SIT project on La Réunion island. Our satyrization of skewed male ratio. 


\section{METHODS}

\section{Mosquito strains, rearing and irradiation conditions}

The Ae. aegypti strain used in this study originated from field collections on La Réunion island. Colonized in the laboratory by the Institute of Research for Development (IRD) for 5 generations before being transferred to the Insect Pest Control Laboratory (IPCL) of the joint FAO/IAEA division of Nuclear Sciences and Applications, the Ae. albopictus La Réunion island strain was then maintained at the IPCL for several generations before these experiments were performed. In order to perform different mating crosses, Ae. albopictus strains from China (Guangzhou wild type strain, provided by Wolbaki) and Italy (Rimini strain, provided by Centro Agricoltura Ambiente (CAA)) were maintained in parallel.

All the strains were reared in $30 \times 40 \times 10 \mathrm{~cm}$ trays at a density of 1 first instar larvae (L1) per $\mathrm{mL}$ under controlled temperature, humidity and lighting conditions $\left(\mathrm{T}=26 \pm 2{ }^{\circ} \mathrm{C}, 70 \pm 10 \mathrm{RH} \%, 12: 12 \mathrm{~h}\right.$ light: dark, including $1 \mathrm{~h}$ dawn and $1 \mathrm{~h}$ dusk). Larvae were fed with IAEA larval diet following the protocol described in the Guidelines for routine rearing (IAEA 2017). Pupae were collected and separated using a glass plate sorter (Focks 1980).

Male pupae were irradiated between 36 and 44 hours of age with 40Gy using a Gamma Cell 220

(Nordion Ltd, Kanata, Ontario, Canada) emitting a dose rate of 90Gy/min.

\section{Experiment 1. Sympatric cross-mating between Ae. aegypti and Ae. albopictus strains from La}

\section{Réunion island}

Male Ae. aegypti and Ae. albopictus were irradiated and crossed with female Ae. albopictus and Ae. aegypti, respectively. Non-irradiated males of each species were also crossed with female mosquitoes of the other species. Non-irradiated male Ae. aegypti and Ae. albopictus were also crossed with virgin female Ae. aegypti and Ae. albopictus, respectively, and used as controls.

Three replicates were performed for each cross with 50 males and 50 females transferred to $15 \times 15 \times$ $15 \mathrm{~cm}$ cages (MegaView Science Co. Ltd., Taiwan) when they were 3 days old for a period of 7 days to ensure enough time was allowed for mating. Females were offered a defibrinated porcine bloodmeal using sausage casings (Grade Specification: 3)26 NC, EDICAS co ltd) for 1 hour (2x 
$30 \mathrm{~min}$ with 10min reheating of the blood sausage in between feedings) on two consecutive days when they were 5-6 days old. Each of the females was transferred to an individual drosophila tube containing a cone of seed germination paper (Grade 6, Size: $580 \times 580 \mathrm{~mm}$, Weight: $145 \mathrm{~g} / \mathrm{m}^{2}$, Sartorius Stedium Biotech) and $10 \mathrm{~mL}$ of water. Females were given 3 days to lay eggs and then dissected to determine their insemination status under a stereomicroscope $(40 \times$ magnification). Before dissection, females were kept in labelled 50mL Falcon tubes (WWR, Germany) in a refrigerator at $4^{\circ} \mathrm{C}$, and samples held in a cold box containing ice to avoid desiccation while other samples were being dissected.

Virgin Ae. aegypti and Ae. albopictus females of the same batch were offered blood meals and were also placed in individual egging tubes to assess their egging capacity.

All eggs were collected, dried for 7 days in the laboratory and allowed to hatch for $20 \mathrm{~h}$ with a hatching solution made of $0.25 \mathrm{~g}$ of CM 0001 Nutrient Broth (Oxoid, Hampshire, UK) and $0.05 \mathrm{~g}$ of yeast diluted in $0.7 \mathrm{~L}$ of deionized water (Zheng et al. 2015).

The number of female mosquitoes still alive after 7 days together with males was recorded for each replicate and survival rate was compared with survival in the conspecific Ae. aegypti mating control.

\section{Experiment 2. Effect of male Ae. albopictus density (ratio) on female Ae. aegypti mating success} To assess whether an increase in male to female ratio would favour satyrization, female Ae. aegypti mosquitoes from La Réunion island were allowed to mate with male Ae. albopictus in a male: female ratio of 3:1 corresponding to 75 male Ae. albopictus and 25 female Ae. aegypti. Three day-old males and females were held in $15 \times 15 \times 15 \mathrm{~cm}$ BugDorm cages (MegaView Science Co. Ltd., Taiwan) for 7 days. The crosses were performed using irradiated males (4 replicates) and non-irradiated males (7 replicates). Females were then dissected to check their insemination status as described above. This experiment was carried out in parallel with Experiment 1 and results of mating crosses could be compared to the insemination rates obtained with a 1:1 male: female ratio (50 males $\times 50$ females).

\section{Experiment 3. Pre-exposure effect on mating success (interspecific-conspecific treatment)}


To assess whether female Ae. aegypti that were pre-exposed to male Ae. albopictus could re-mate with their conspecific male Ae. aegypti, 4 to 5 day-old female Ae. aegypti (La Réunion island strain) were pre-exposed to irradiated and non-irradiated male Ae. albopictus (La Réunion island strain). Females were removed after 7 days and were offered to irradiated and non-irradiated male Ae. aegypti (La Réunion island strain) for another 7 days. Females were then blood fed for 2 consecutive days and eggs collected before females were dissected under a microscope to determine insemination status. We hypothesized that if female Ae. aegypti were inseminated by non-irradiated Ae. albopictus males, they would not be able to lay fertile eggs even if they had a blood meal.

Fifty adults were included in each cross in a 1:1 male: female ratio in Bugdorm cages $(15 \times 15 \times$ 15cm) (MegaView Science Co. Ltd., Taiwan).

An experimental design was used which ensured that female Ae. aegypti that were pre-exposed to male Ae. albopictus, had not been inseminated (Table 1), and female insemination and egg hatch rates were observed.

\section{Experiment 4. Effect of geographic origin on mating success (allopatric crosses)}

Since we observed resistance to satyrization against Ae. albopictus in the sympatric cross experiment, we explored the allopatric effect to better understand the mating behavior of the La Réunion island strain of Ae. aegypti. Several crosses were performed using irradiated and non-irradiated males of the Ae. albopictus strains from La Réunion island, China (Guangzhou wild type strain) and Italy (Rimini strain).

Female Ae. aegypti mosquitoes from La Réunion island were crossed for 7 days with non-irradiated or combinations. In each interspecific treatment (Ae. aegypti female $\times$ Ae. albopictus male), 30 males and 30 females, 3 days old, from each strain were housed in $15 \times 15 \times 15 \mathrm{~cm}$ BugDorm cages (MegaView Science Co. Ltd., Taiwan). In addition, conspecific control crosses (Ae. albopictus female $\times$ Ae. albopictus male, and Ae. aegypti female $\times$ Ae. aegypti male, La Réunion island strain) were carried out using the same number of males and females for each strain. The number of females that were successfully inseminated was recorded (as described for Experiment 1) and results were compared to 
the interspecific crosses and to the conspecific control crosses. Egg hatch was performed as described for Experiment 1 for batches that were collected from females mated with non-irradiated males.

\section{Statistics}

Statistical analyses were performed and graphs drawn using RStudio Team (2016). The proportion of inseminated females was calculated as the number with at least one spermathecae filled with sperm divided by the number of dissected females. The proportion egg hatch was calculated from the number of hatched eggs divided by the total number of eggs laid per individual female (Experiment 1) or per group of females in a cage (Experiments 3 and 4). The proportions were transformed following the Freeman-Tukey method (arcsine transformed data). An analysis of variance (ANOVA) was then performed followed by a Tukey multiple comparison to compare means of each crossed pair. A paired t-test was performed to compare egg hatch between pre-exposed and non-exposed females (Preexposure effect on mating success experiment).

The survival rate (Experiment 1) was analyzed using a generalized binomial linear mixed-effects model fit by maximum likelihood (Laplace approximation) with logit link with the survival rate, defined as dependent variable, and type of mating pairs (cross) as fixed effects and replicates as a random effect. The best model was selected based on the lowest corrected Akaike information criterion (AICc), and the significance of fixed effects was tested using the likelihood ratio test (Burnham and Anderson, 2003; Hurvich and Tsai, 1995).

The statistical significance for all experiments was determined at the $\alpha=0.05$ level. 


\section{RESULTS}

Experiment 1. Sympatric cross-mating between Ae. aegypti and Ae. albopictus strains from La

213

\section{Réunion island}

There was no insemination between sympatric species from La Réunion island strains either when non-irradiated or irradiated male Ae. aegypti or Ae. albopictus were caged with female Ae. albopictus $(\mathrm{n}=82$, mean $( \pm \mathrm{SE})=0 \pm 0 \%$ and $\mathrm{n}=72$, mean $( \pm \mathrm{SE})=0 \pm 0 \%)$ or Ae. aegypti $(\mathrm{n}=28$, mean $( \pm \mathrm{SE})$ $=0 \pm 0 \%$ and $n=41$, mean $( \pm S E)=0 \pm 0 \%)$, respectively, compared to the conspecific mating controls (Ae. albopictus: $\mathrm{n}=58$, mean $( \pm \mathrm{SE})=99.2 \pm 0.01 \% ;$ Ae. aegypti: $\mathrm{n}=71$, mean $( \pm \mathrm{SE})=100 \pm 0 \%)($ Figure $\left.1, \mathrm{~F}_{(5,12)}=735.6, p<0.0001\right)$. A Tukey multiple comparisons of means did not show any difference in insemination rate regardless of the cross type between irradiated or non-irradiated males of $A e$. albopictus or Ae. aegypti and non-irradiated females of Ae. aegypti and Ae. albopictus, respectively ( $p$ $>0.05)$

Regardless of the male status (irradiated or non-irradiated) the females exposed to interspecific mating, and virgin females, laid a lower number of eggs per female than the females of the conspecific mating control crosses (Interspecific: (C3-6): 146 eggs ( $n=223)$; virgin females (Faeg-Falbo): 92 eggs $(n=77)$, controls $(C 1-2)$ : 2 047eggs $(n=129))$. None of eggs from interspecific mating crosses and virgin females hatched compared to the controls (Figure $2, \mathrm{~F}_{(7,46)}=84.73, p<0.0001$ ). Interspecific mating was more detrimental to female Ae. aegypti survival than to Ae. albopictus (Table $2, p<0.0001)$.

\section{Experiment 2. Effect of male Ae. albopictus density (ratio) on female Ae. aegypti mating success}

Increasing the ratio of male: female to 3:1 in favour of male Ae. albopictus did not significantly increase the satyrization effect on female Ae. aegypti (La Réunion island) judged by insemination rates for both non-irradiated (t-test, ratio 1:1: mean $( \pm \mathrm{SE})=0 \pm 0 \%, \mathrm{n}=28$, ratio $3: 1:$ mean $( \pm \mathrm{SE})=2 \pm 0.1 \%$, $\mathrm{n}=169, p=0.26)$ and irradiated (t-test, ratio $1: 1:$ mean $( \pm \mathrm{SE})=0 \pm 0 \%, \mathrm{n}=41$, ratio $3: 1:$ mean $( \pm \mathrm{SE})$ 
$=0 \pm 0 \%, \mathrm{n}=101, p=1)$ male Ae. albopictus. All these crosses had negligible insemination rates compared to conspecific mating (controls) $\left(\mathrm{F}_{(7,21)}=272.8, p<0.0001\right)$.

\section{Experiment 3. Pre-exposure effect on mating success}

When female Ae. aegypti were pre-exposed to non-irradiated or irradiated male Ae. albopictus, there was no insemination (Figure 3. C5: mean $( \pm \mathrm{SE})=0 \pm 0 \%, \mathrm{n}=90$, and C6: mean $( \pm \mathrm{SE})=0 \pm 0 \%, \mathrm{n}=121)$ whereas groups of females that were pre-exposed to male Ae. albopictus were inseminated by their male Ae. aegypti conspecifics (Figure 3. C7: mean $( \pm \mathrm{SE})=100 \pm 0 \%, \mathrm{n}=106$, and C8: mean $( \pm \mathrm{SE})$ $=95.99 \pm 0 \%, \mathrm{n}=146)$. No difference in female insemination rates was observed between pre-exposed and non-exposed females ( $p=0.27$ ) or between pre-exposed females and controls (Figure 3. C1-3 vs C7-8) $(p>0.05)$.

Female Ae. aegypti that were pre-exposed to male Ae. albopictus successfully laid fertile eggs when they then mated with their male Ae. aegypti conspecifics, and mean egg hatch was lower but not significantly different between the non-exposed (mean $( \pm$ SE $)=95.99 \pm 0.008 \%)$ and pre-exposed females $($ mean $( \pm \mathrm{SE})=91.61 \pm 0.02 \%)(\mathrm{t}$-test: $\mathrm{t}=2.0576, \mathrm{df}=4, p=0.1)$.

\section{Experiment 4. Effect of geographic origin on mating success (allopatric crosses)}

A greater female insemination rate was observed when conspecific mating was compared to the interspecific mating groups, regardless of the male origin or irradiation status $\left(\right.$ Table $3, \mathrm{~F}_{(13,23)}=$ 229.1, $p<0.0001)$. Neither geographic origin nor irradiation status of male Ae. albopictus had an impact on female Ae. aegypti insemination rate, confirming the conclusion that allopatric and sympatric effects were similar when the La Réunion island strain of Ae. aegypti was used in these experiments (Table 3, $>>0.05)$.

We observed a significantly lower egg hatch in interspecific than conspecific crosses irrespective of the male origin (Table $\left.3, \mathrm{~F}_{(13,23)}=182.9, p<0.0001\right)$. 


\section{DISCUSSION}

The objective of this study was to assess the level of reproductive interference between male $A e$. albopictus and female Ae. aegypti and to discuss the strategy of management of the two vector species in a sympatric area. In laboratory conditions almost no satyrization effect was observed between sympatric populations of Ae. aegypti and Ae. albopictus colonised from La Réunion island, even when the male Ae. albopictus to female Ae. aegypti ratio was increased to 3:1. Female Ae. aegypti previously mated to male Ae. albopictus were not prevented from being inseminated by conspecific male Ae. aegypti. Satyrization did not occur between allopatric Ae. albopictus and Ae. aegypti strains from La Réunion island either. An Ae. aegypti strain from La Réunion island has therefore developed full resistance to satyrization (anti-satyrization behavior).

Many reasons could explain the observed low level of satyrization. Bargielowki et al. (2013; 2015) have previously described sympatric field populations that have co-existed long enough to evolve resistance to cross-mating and showed that Ae. aegypti females allopatric to Ae. albopictus are more susceptible to interspecific insemination by Ae. albopictus (Lounibos et al. 2016). Cage experiments and field observations indicate that Ae. albopictus males are capable of satyrizing females of other species of the Stegomyia subgenus, potentially leading to competitive displacement, and even extinction, especially of endemic species on islands (Bargielowki et al. 2015). In contrast, in our study even an increase in ratios in favour of male Ae. albopictus did not significantly increase insemination of female Ae. aegypti. One study has pointed to the implication of population density on mating behavior (Marcela et al. 2015), which found that male density significantly increased swarming behavior, number of mating pairs, and egg production of hetero-specific females, but not female insemination. They also found that Ae. aegypti males mate more readily with hetero-specific females than do Ae. albopictus males and so if Ae. aegypti were released into the field they may mate with both Ae. aegypti and Ae. albopictus females, and reduce populations of both species by preventing offspring. There is no evidence that this would be the case on La Réunion island since we observed low reproductive success when crosses were performed in both directions. In addition, we observed that interspecific mating was detrimental to female Ae. aegypti survival. It has been previously documented that interspecific copulation and hybridization can reduce female reproductive success, 
but interspecific sexual harassment, which does not always result in interspecific copulation, can also adversely affect individual reproductive success and longevity by suppressing both sugar and blood feeding (Soghigian et al. 2014). In white butterflies (Leptidea spp.), for example, the prolonged mating ritual of hetero-specific males decreases the number of opportunities that females have to mate with conspecific males even when interspecific copulation does not take place (Friberg et al. 2013). Similarly, in bean weevils (Callosobruchus spp.), males persistently chase hetero-specific females, causing reductions in the oviposition rate and shortened longevity of these females (Kishi et al. 2009). conspecific male Ae. aegypti demonstrating that the La Réunion island Ae. aegypti strain has developed a resistance to satyrization. Carrasquilla and Lounibos (2015) have showed that Ae. aegypti females, previously exposed to Ae. albopictus males, were rendered refractory to subsequent conspecific mating even when their spermathecae contained no hetero-specific sperm. Additional experiments demonstrated transfer of labelled semen from Ae. albopictus males to Ae. aegypti females and low production of viable eggs of females housed with conspecific males, following exposure to Ae. albopictus males, and confirmed higher incidence of satyrization than expected, based on heterospecific insemination rates. We did not observe this result after pre-exposing Ae. aegypti females to Ae. albopictus for 7 days before replacing male Ae. albopictus by male Ae. aegypti mosquitoes. It has been shown that interspecific pairs needed more time together before mating occurred. Bargielowki et al. (2015) found that when female Ae. aegypti were exposed for up to 3 weeks, interspecific

310 insemination increased significantly from $1 \%$ after 1 day, to $10 \%$ after 1 week and to more than $50 \%$ 311 after 3 weeks. However, assuming that most released sterile males will survive around 1 week in the field, it is unlikely that most released males would be able to find and mate with females after 3 weeks in the wild (Bellini et al. 2010; Iyaloo et al. 2019). These results indicate that in areas where Ae. aegypti and Ae. albopictus co-occur, releasing sterile male Ae. albopictus may not suppress Ae. aegypti populations. It would be more beneficial to suppress the species with the smallest population, before further planning to control the second species, assuming the epidemiological impact of each species was equal. 
bioRxiv preprint doi: https://doi.org/10.1101/2020.02.10.942839; this version posted February $12,2020$. The copyright holder for this preprint (which was not certified by peer review) is the author/funder, who has granted bioRxiv a license to display the preprint in perpetuity. It is made available under aCC-BY-NC-ND 4.0 International license.

In our study, female Ae. aegypti pre-exposed to male Ae. albopictus produced eggs which had similar egg hatch when re-mated with their conspecifics, meaning that females had not been inseminated by the Ae. albopictus males. Those females which later mated with their conspecifics and laid eggs were apparently fully fertilized by conspecific sperm. However, it has been shown that the satyrization effect could be underestimated when evaluation of mating status of females is based on whether the spermathecae were filled with sperm or not (Carrasquilla and Lounibos, 2015). It therefore cannot be ruled out that some females might have been inseminated when pre-exposed to Ae. albopictus based on the variation observed in egg hatch. Bargielowski et al. (2015) demonstrated that multiple inseminations can occur in older female Ae. aegypti when the effects of accessory gland proteins have worn off, and in females mated to sperm-depleted males. In any case, hetero-specific sperm is known to be stored in separate spermathecae (Bargielowski et al. 2015) and so was presumably not significantly used for egg fertilization.

Allopatric Ae. albopictus males did not perform better than sympatric males and anti-satyrization effects seem to protect against allopatric populations. This shows that resistance to one strain confers resistance to others. Honórios et al. (2018) demonstrated that only some populations of Ae. albopictus are capable of satyrization. Female Ae. aegypti from populations allopatric to Ae. albopictus in the field were more susceptible to interspecific mating than females from sympatric populations, and selection experiments in cages confirmed the rapid development of resistance to satyrization in the laboratory, as well as changes in behavior toward conspecifics associated with increased satyrization resistance (Bargielowski and Lounibos 2014). The fact that the Ae. aegypti populations persist in La Réunion island ravines as opposed to urban environments could be due to some genetic differentiation from domestic subspecies. Lounibos and Juliano (2018) have recently pointed out that the feral subspecies Ae. aegypti formosus is expected to behave differently than the domestic subspecies but populations of this species from Madagascar, La Réunion island and Mayotte have not been tested yet for genetic distinctiveness from Ae. aegypti (aegypti) to the best of our knowledge. In any case, a signature of selection in the Ae. aegypti genome to a specific type of interspecific interaction (mating) was found by Reiskind et al. (2017) allowing the identification of its genetic basis. 
345 When considering a regional approach for Aedes control using the SIT, compatibility of strains as well

346 as species may be important as it would allow strains to be imported for release from nearby countries

347 where they can be more easily reared and/or irradiated. Damiens et al. (2016) demonstrated that male

348 Ae. albopictus from Mauritius and Seychelles islands, about 50-200 km away from La Réunion island,

349 were compatible and could successfully inseminate female Ae. albopictus regardless of their origin. A

350 regional SIT mass-rearing programme could therefore be envisaged, with a good transportation

351 method, but the release of sterile Ae. albopictus males may not have the added benefit of satyrizing the

352 local Ae. aegypti population if an overflooding of irradiated male Ae. albopictus leads to similar

353 results.

354 The development of resistance to satyrization in the Ae. aegypti strain shows that strong competition

355 between the sympatric Ae. aegypti and Ae. albopictus probably occurs on La Réunion island. An SIT

356 project against Ae. albopictus would not have an effect on Ae. aegypti populations, and other

357 mechanisms such as larval competition probably explain the current geographical retraction of Ae.

358 aegypti to the ravines. Bagny et al. (2013) observed that this narrow distribution of Ae. aegypti was

359 due to its poorer ability to cope with unfavourable temperatures and to its lower competition between

360 larvae for resources compared to Ae. albopictus (Juliano 2009). The two species may co-exist as long

361 as the dominant Ae. albopictus is present and the resistance could be maintained by satyrization

362 pressure (Bargielowski et al. 2019). Global climate change may favour an increase in the population

363 size of Ae. aegypti (Juliano et al. 2004) which is a greater vector of arboviral diseases including

364 dengue, chikungunya, yellow fever and Zika. Therefore, suppressing or eliminating Ae. albopictus will

365 likely promote expansion of Ae. aegypti (HCB Scientific Committee 2017). Whilst it may be

366 important to target the most epidemiologically important vector first (Alphey et al. 2010), considering

367 its limited distribution, the eradication of Ae. aegypti population may be seen as a first priority. 
bioRxiv preprint doi: https://doi.org/10.1101/2020.02.10.942839; this version posted February 12, 2020. The copyright holder for this preprint (which was not certified by peer review) is the author/funder, who has granted bioRxiv a license to display the preprint in perpetuity. It is made available under aCC-BY-NC-ND 4.0 International license. 


\section{REFERENCES}

Alphey L, Benedict M, Bellini R, Clark GG, Dame DA, Service MW, Dobson SL. 2010. Sterile-insect methods for control of mosquito-borne diseases: an analysis. Vector Borne Zoonotic Dis. 10:295-311.

Arrêté No 2019-2213 autorisant l'IRD a procéder à des lâchers de moustiques stériles en vue d'études entomologiques au sein du quartier Duparc à Sainte-Marie - 2.9 Mo - 13/06/2019.

Bagny L, Delatte H,Quilici S, Fontenille D. 2009. Progressive decrease in Aedes aegypti distribution in Reunion Island since the 1900s. Journal of Medical Entomology. 46:1541-1545.

Bagny Beilhe L, Delatte H, Juliano SA, Fontenille D, Quilici S. 2013. Ecological interactions in Aedes species on Reunion Island. Med Vet Entomol.27:387-97.

Bargielowski IE, Lounibos LP, Carrasquilla MC. 2013. Evolution of resistance to satyrization through reproductive character displacement in populations of invasive dengue vectors. Proc Natl Acad Sci U S A.110:2888-92.

Bargielowski I, Lounibos LP. 2014. Rapid evolution of reduced receptivity to interspecific mating in the dengue vector Aedes aegypti in response to satyrization by invasive Aedes albopictus. Evol Ecol. 28:193-203.

Bargielowski IE, Blosser E, Lounibos LP. 2015. The effects of interspecific courtship on the mating success of Aedes aegypti and Aedes albopictus (Diptera: Culicidae) males. Ann. Entomol. Soc. Am. 108:513-518.

Bargielowski I, Honório NA, Blosser EM, Lounibos LP. 2019. Rapid Loss of Resistance to Satyrization in Invasive Mosquitoes and the Effects of Age on Interspecific Mating Frequency. $\mathbf{J}$ Med Entomol. 56:329-333.

Bellini R, Albieri A, Balestrino F, Carrieri M, Porretta D, Urbanelli S, Calvitti M, Riccardo MR, Maini S. 2010. Dispersal and survival of Aedes albopictus (Diptera: Culicidae) males in Italian urban areas and significance for sterile insect technique application. J Med Entomol. 7:10821091.

Benedict MQ, Levine RS, Hawley WA, Lounibos LP.2007. Spread of the tiger: global risk of invasion by the mosquito Aedes albopictus. Vector Borne Zoonotic Dis. 7:76-85. 
Bhatt S, Gething PW, Brady OJ, Messina JP, Farlow AW, Moyes CL, Drake JM, Brownstein JS, Hoen AG, Sankoh O, Myers MF, George DB, Jaenisch T, Wint GRW, Simmons CP, Scott TW, Farrar JJ, Hay SI. 2013.The global distribution and burden of dengue. Nature.496:504-507.

401

402

Bournez L, Cangi N, Lancelot R, Pleydell DRJ, Stachurski F, Bouyer J, Martinez D, Lefrançois T, Neves L, Pradel J. 2015. Parapatric distribution and sexual competition between two tick species, Amblyomma variegatum and A. hebraeum (Acari, Ixodidae), in Mozambique. Parasit Vectors. 8:504.

Burford Reiskind MO, Labadie P, Bargielowski I, Lounibos LP, Reiskind MH. 2018. Rapid evolution and the genomic consequences of selection against interspecific mating. Mol Ecol. 27:36413654.

Burnham KP, Anderson DR. 2003. Model selection and multimodel inference: a practical informationtheoretic approach. Springer Science \& Business Media.

Carrasquilla MC, Lounibos LP. 2015. Satyrization without evidence of successful insemination from interspecific mating between invasive mosquitoes. Biol Lett. 11: 20150527.

Chouin-Carneiro T, Vega-Rua A, Vazeille M, Yebakima A, Girod R, Goindin D, Dupont-Rouzeyrol M, Lourenço-de-Oliveira R, Failloux AB. 2016. Differential Susceptibilities of Aedes aegypti and Aedes albopictus from the Americas to Zika Virus. PLoS Negl Trop Dis. 10:e0004543.

Conseil scientifique de l'Agence française pour la biodiversité - Séance des 26-27 avril 2018 Délibération $n^{\circ} \mathrm{CS} / 2018-01$.

Damiens D, Lebon C, Wilkinson DA, Dijoux-Millet D, Le Goff G, Bheecarry A, Gouagna LC. 2016. Cross-Mating Compatibility and Competitiveness among Aedes albopictus Strains from Distinct Geographic Origins - Implications for Future Application of SIT Programs in the South West Indian Ocean Islands. PLoS One. 11:e0163788.

de Araújo TVB, Rodrigues LC, de Alencar Ximenes RA, de Barros Miranda-Filho D, Montarroyos UR, de Melo APL, Valongueiro S, de Albuquerque MFPM, Souza WV, Braga C, Filho SPB, Cordeiro MT, Vazquez E, Di Cavalcanti Souza Cruz D, Henriques CMP, Bezerra LCA, da Silva Castanha PM, Dhalia R, Marques-Júnior ETA, Martelli CMT; investigators from the Microcephaly Epidemic Research Group; Brazilian Ministry of Health; Pan American Health 
Dyck VA, Hendrichs JP, Robinson AS. 2005. The Sterile Insect Technique: Principles and Practice in Area-Wide Integrated Pest Management. Dordrecht: Springer.

FAO/IAEA. Guidelines for routine colony maintenance of Aedes mosquito species - Version 1.0

Focks DA. 1980. An improved separator for the developmental stages, sexes, and species of mosquitoes (Diptera: Culicidae). J Med Entomol.17:567-568.

Friberg M, Leimar O, Wiklund C. 2013. Heterospecific courtship, minority effects and niche separation between cryptic butterfly species. J Evol Biol. 26:971-979. 
Hurvich CM, Tsai CL. 1995. Model selection for extended quasi-likelihood models in small samples. Biometrics. 1077-1084.

Iyaloo DP, Damiens D, Sunita F, Elahee KB, Bheecarry A. 2019. Dispersal and survival of radiosterilised male Aedes albopictus Skuse (Diptera: Culicidae) and estimation of the wild populations in view of an sterile insect technique programme in Pointe des Lascars, Mauritius. Int J Trop Insect Sci.39: 63.

Juliano SA, Lounibos LP, O'Meara GF.2004. A field test for competitive effects of Aedes albopictus on Aedes aegypti in South Florida: differences between sites of coexistence and exclusion? Oecologia 139:583-593.

Juliano SA. 2009. Species interactions among larval mosquitoes: Context dependence across habitat gradients. Ann Rev Entomol.54:37-56.

Kaplan L, Kendell D, Robertson D, Livdahl T, Khatchikian C. 2010. Aedes aegypti and Aedes albopictus in Bermuda: extinction, invasion, invasion and extinction. Biol Invasions.12:3277-88.

Kishi S, Nishida T, Tsubaki Y. 2009. Reproductive interference determines persistence and exclusion in species interactions. J Anim Ecol. 78:1043-1049.

Knipling EF. 1959. Sterile-Male Method of Population Control: Successful with some insects, the method may also be effective when applied to other noxious animals. Science.130: 902-904.

Kyle JL, Harris E. 2008. Global spread and persistence of dengue. Annu Rev Microbiol.62:71-92.

Levy-Blitchtein S, Del Valle-Mendoza J. 2016. Zika virus is arriving at the American continent. Asian Pac J Trop Med.9:1019-1021.

Lounibos LP. 2002. Invasions by insect vectors of human disease. Annu Rev Entomol.47:233-66.

Lounibos LP, Bargielowski I, Carrasquilla MC, Nishimura N. 2016. Coexistence of Aedes aegypti and Aedes albopictus (Diptera: Culicidae) in Peninsular Florida Two Decades After Competitive Displacements. J Med Entomol. 53:1385-1390.

Lounibos LP, Juliano SA. 2018. Where Vectors Collide: The Importance of Mechanisms Shaping the Realized Niche for Modeling Ranges of Invasive Aedes Mosquitoes. Biol Invasions. 20:19131929. 
Marcela P, Abu Hassan A, Hamdan A, Dieng H, Kumara TK. 2015."Interspecific Cross-Mating Between Aedes aegypti and Aedes albopictus Laboratory Strains: Implication of Population Density on Mating Behaviors,". J Am Mosq Control Assoc. 31:313-320.

Nasci RS, Hare SG, Willis FS. 1989. Interspecific mating between Louisiana strains of Aedes albopictus and Aedes aegypti in the field and laboratory. J Am Mosq Control Assoc.5:416-21.

Paupy C, Ollomo B, Kamgang B, Moutailler S, Rousset D, Demanou M, Hervé JP, Leroy E, Simard F. 2010. Comparative role of Aedes albopictus and Aedes aegypti in the emergence of Dengue and Chikungunya in central Africa. Vector Borne Zoonotic Dis. 10:259-66.

Ribeiro JMC. 1988. Can satyrs control pests and vectors? J Med Entomol.25:431-440.

RStudio Team (2016). RStudio: Integrated Development for R. RStudio, Inc., Boston, MA URL http://www.rstudio.com/.

Soghigian J, Gibbs K, Stanton A, Kaiser R, Livdahl T. 2014. Sexual harassment and feeding inhibition between two invasive dengue vectors. Environ. Health Insights.8: 61-66.

Tripet F, Lounibos LP, Robbins D, Moran J, Nishimura N, Blosser EM. 2011. Competitive reduction by satyrization? Evidence for interspecific mating in nature and asymmetric reproductive competition between invasive mosquito vectors. Am J Trop Med Hyg.85:265-70.

World Health Organization. 2017. Global vector control response 2017-2030.

World Health Organization. 2019. https://www.who.int/csr/don/01-may-2018-dengue-reunion/en/ (Assessed on 11 Sep 2019).

Zheng ML, Zhang DJ, Damiens DD, Lees RS, Gilles JR. 2015. Standard operating procedures for standardized mass rearing of the dengue and chikungunya vectors Aedes aegypti and Aedes albopictus (Diptera: Culicidae). II. Egg storage and hatching. Parasit Vectors.8:348. 


\section{FIGURE LEGENDS}

\section{Figure 1. Sympatric cross-mating between Ae. aegypti and Ae. albopictus strains from La}

Réunion island. $\mathrm{C}$ denotes the cross and numbers (1-6) are related to the cross identity. The number of dissected females (n) per cross were $\mathrm{C} 1=$ control Ae. albopictus (non-irradiated), n=58), $\mathrm{C} 2=$ control Ae. aegypti (non-irradiated), n=71, C3= male Ae. albopictus (non-irradiated) $\times$ female Ae. aegypti, $\mathrm{n}=28, \mathrm{C} 4=$ male Ae. albopictus (irradiated) $\times$ female Ae. aegypti, $\mathrm{n}=41, \mathrm{C} 5=$ male Ae. aegypti (non-irradiated) $\times$ female Ae. albopictus, $\mathrm{n}=82, \mathrm{C} 4=$ male Ae. aegypti (irradiated $) \times$ female Ae. albopictus, $\mathrm{n}=72$.

\section{Figure 2. Egg hatch in sympatric crosses between Ae. aegypti and Ae. albopictus strains from La}

Réunion island. $\mathrm{C}$ denotes the cross and numbers (1-6) are related to the cross identity. $\mathrm{C} 1=$ control Ae. albopictus (non-irradiated), $\mathrm{C} 2=\operatorname{control}$ Ae. aegypti (non-irradiated), $\mathrm{C} 3=$ male Ae. albopictus (non-irradiated) $\times$ female Ae. aegypti, $\mathrm{C} 4=$ male Ae. albopictus (irradiated) $\times$ female Ae. aegypti, $\mathrm{C} 5=$ male Ae. aegypti (non-irradiated) $\times$ female Ae. albopictus, $\mathrm{C} 4=$ male Ae. aegypti (irradiated) $\times$ female Ae. albopictus.

Figure 3. Pre-exposure effect on mating success. $C$ denotes the cross and numbers (1-8) are related to the cross identity. $\mathrm{C} 1=$ control Ae. aegypti (non-irradiated), $\mathrm{C} 2=$ control Ae. aegypti (irradiated), $\mathrm{C} 3=$ control Ae. albopictus (non-irradiated), $\mathrm{C} 4=$ control Ae. albopictus (irradiated), $\mathrm{C} 5=$ male Ae . albopictus (non-irradiated) $\times$ female Ae. aegypti, C6 = male Ae. albopictus (irradiated) $\times$ female Ae. aegypti, $\mathrm{C} 7=$ male Ae. aegypti (non-irradiated) $\times$ female Ae. aegypti (non-exposed to male $A e$. albopictus), C8 = male Ae. aegypti (non-irradiated) $\times$ female Ae. aegypti (pre-exposed to male Ae. albopictus). 
TABLES AND TABLE LEGENDS

Table 1. Experimental design of the interspecific-conspecific treatments

\begin{tabular}{cccccccc}
\hline cross & status & $\begin{array}{c}\text { number } \\
\text { of } \\
\text { replicates }\end{array}$ & male & female & $\begin{array}{c}\text { irradiated } \\
\text { males }\end{array}$ & $\begin{array}{c}\text { fecundity } \\
\text { and fertility } \\
\text { checks }\end{array}$ & $\begin{array}{c}\text { dissection for } \\
\text { insemination } \\
\text { status check }\end{array}$ \\
\hline C1 & control & 5 & AEG & AEG & YES & NO & YES \\
C2 & control & 4 & AEG & AEG & NO & NO & YES \\
C3 & control & 4 & ALBO & ALBO & YES & NO & YES \\
C4 & control & 4 & ALBO & ALBO & NO & NO & YES \\
C5 & pre-exposed & 4 & ALBO & AEG & YES & NO & YES \\
C6 & pre-exposed & 4 & ALBO & AEG & NO & NO & YES \\
C7 & control & 5 & AEG & AEG & NO & YES & YES \\
C8 & pre-exposed & 5 & ALBO & AEG & NO & YES & YES
\end{tabular}

AEG and ALBO stand for Ae. aegypti and Ae. albopictus respectively; $\mathrm{C}$ for cross and numbers 1-8 
bioRxiv preprint doi: https://doi org/10.1101/2020.02 10.942839; this version posted February 12, 2020. The copyright holder for this preprint (which was not certified by peer review) is the author/funder, who has granted bioRxiv a license to display the preprint in perpetuity. It is made available under aCC-BY-NC-ND 4.0 International license.

Table 2. Comparison of survival rate between female Ae. aegypti in the cross-mating between sympatric Ae. aegypti and Ae. albopictus strains from La Réunion island

\begin{tabular}{lllll}
\hline & Estimate & Std. Error & $\mathrm{z}$ value & $p(>|\mathrm{z}|)$ \\
\cline { 2 - 5 } (Intercept) & $5.93 \mathrm{E}-16$ & $1.63 \mathrm{E}-01$ & 0 & 1 \\
crossctralbo & $-2.96 \mathrm{E}-01$ & $2.32 \mathrm{E}-01$ & -1.272 & 0.2032 \\
crossMaegFalbo & $5.04 \mathrm{E}-01$ & $2.02 \mathrm{E}-01$ & 2.492 & $0.0127 *$ \\
crossMalboFaeg & $-1.05 \mathrm{E}+00$ & $2.10 \mathrm{E}-01$ & -4.987 & $6.13 \mathrm{e}-07 * * *$
\end{tabular}

Std. standard

Ctrlalbo stands for control Ae. albopictus cross; MaegFalbo=male Ae. aegypti $\times$ female Ae. albopictus; MalboFaeg=male Ae. albopictus $\times$ female Ae. aegypti 
Table 3. Mean insemination and egg hatch rates $( \pm \mathrm{SE})$ in crosses between female Ae. aegypti (La Réunion island strain) and Ae. albopictus males from China, Italy (allopatric) and La Réunion island (sympatric).

\begin{tabular}{|c|c|c|c|c|c|}
\hline \multirow[t]{2}{*}{ Mating type } & \multicolumn{2}{|c|}{ Male } & \multirow[t]{2}{*}{ Female } & \multirow{2}{*}{$\begin{array}{c}\text { Insemination rates } \\
(\%)\end{array}$} & \multirow[t]{2}{*}{ hatch rates $(\%)$} \\
\hline & irradiated & $\begin{array}{c}\text { non- } \\
\text { irradiated }\end{array}$ & & & \\
\hline \multirow{2}{*}{ interspecific } & China & & Réunion & $0.92 \pm 0.92^{\mathrm{a}}(95)$ & NA \\
\hline & & China & Réunion & $0 \pm 0^{a}(82)$ & $0 \pm 0^{\mathrm{a}}$ \\
\hline \multirow{2}{*}{ conspecific } & China & & China & $100 \pm 0^{\mathrm{b}}(24)$ & NA \\
\hline & & China & China & $100 \pm 0^{\mathrm{b}}(48)$ & $100 \pm 0^{\mathrm{b}}$ \\
\hline \multirow{2}{*}{ interspecific } & Réunion & & Réunion & $1.92 \pm 1.11^{\mathrm{a}}(94)$ & NA \\
\hline & & Réunion & Réunion & $1.33 \pm 1.33^{\mathrm{a}}(74)$ & $0 \pm 0^{\mathrm{a}}$ \\
\hline \multirow{2}{*}{ conspecific } & Réunion & & Réunion & $100 \pm 0^{\mathrm{b}}(57)$ & NA \\
\hline & & Réunion & Réunion & $100 \pm 0^{\mathrm{b}}(54)$ & $71.8 \pm 2.7^{\mathrm{c}}$ \\
\hline \multirow{2}{*}{ interspecific } & Italy & & Réunion & $0 \pm 0^{a}(99)$ & NA \\
\hline & & Italy & Réunion & $5.5 \pm 3.68^{\mathrm{a}}(77)$ & $0 \pm 0^{\mathrm{a}}$ \\
\hline \multirow{2}{*}{ conspecific } & Italy & & Italy & $100 \pm 0^{\mathrm{b}}(50)$ & NA \\
\hline & & Italy & Italy & $100 \pm 0^{\mathrm{b}}(57)$ & $83.5 \pm 1.55^{\mathrm{c}}$ \\
\hline \multirow{2}{*}{ conspecific } & Réunion* & & Réunion & $100 \pm 0^{\mathrm{b}}(72)$ & NA \\
\hline & & Réunion* & Réunion & $100 \pm 0^{\mathrm{b}}(54)$ & $89.8 \pm 2.11^{\mathrm{c}}$ \\
\hline
\end{tabular}

'Interspecific' stands for crosses between female Ae. aegypti, La Réunion island strain and Ae. albopictus (strain from China, Italy, La Réunion island) and 'conspecific' for control mating between male and female of the same species. Réunion* = male Ae. aegypti from La Réunion island. Numbers into parentheses represent the number of dissected females for insemination assessment. Different letters show significant difference between groups. 
bioRxiv preprint doi: https://doi.org/10.1101/2020.02.10.942839; this version posted February 12, 2020. The copyright holder for this preprint (which was not certified by peer review) is the author/funder, who has granted bioRxiv a license to display the preprint in perpetuity. It is made available under aCC-BY-NC-ND 4.0 International license.

\section{FIGURES}

565

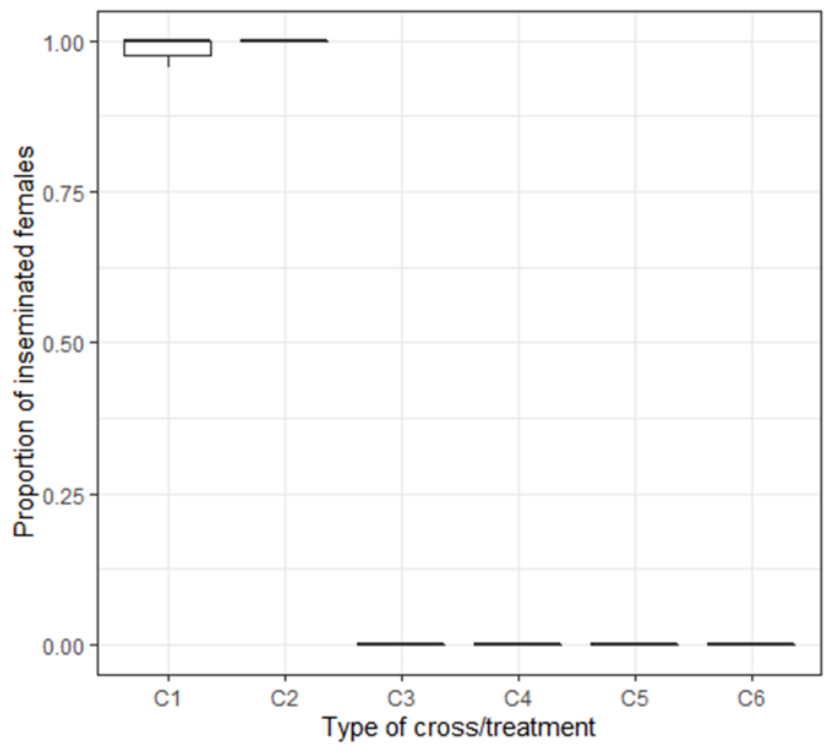

566

567

568

Figure 1 
bioRxiv preprint doi: https://doi.org/10.1101/2020.02.10.942839; this version posted February 12, 2020. The copyright holder for this preprint (which was not certified by peer review) is the author/funder, who has granted bioRxiv a license to display the preprint in perpetuity. It is made available under aCC-BY-NC-ND 4.0 International license.

Figure 2

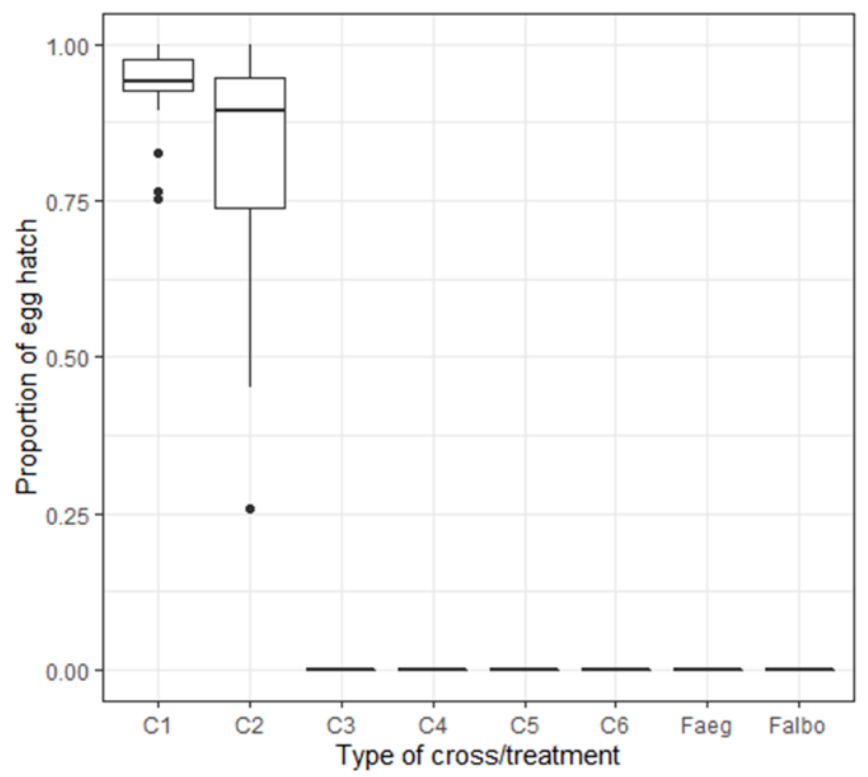


bioRxiv preprint doi: https://doi.org/10.1101/2020.02.10.942839; this version posted February 12, 2020. The copyright holder for this preprint (which was not certified by peer review) is the author/funder, who has granted bioRxiv a license to display the preprint in perpetuity. It is made available under aCC-BY-NC-ND 4.0 International license.

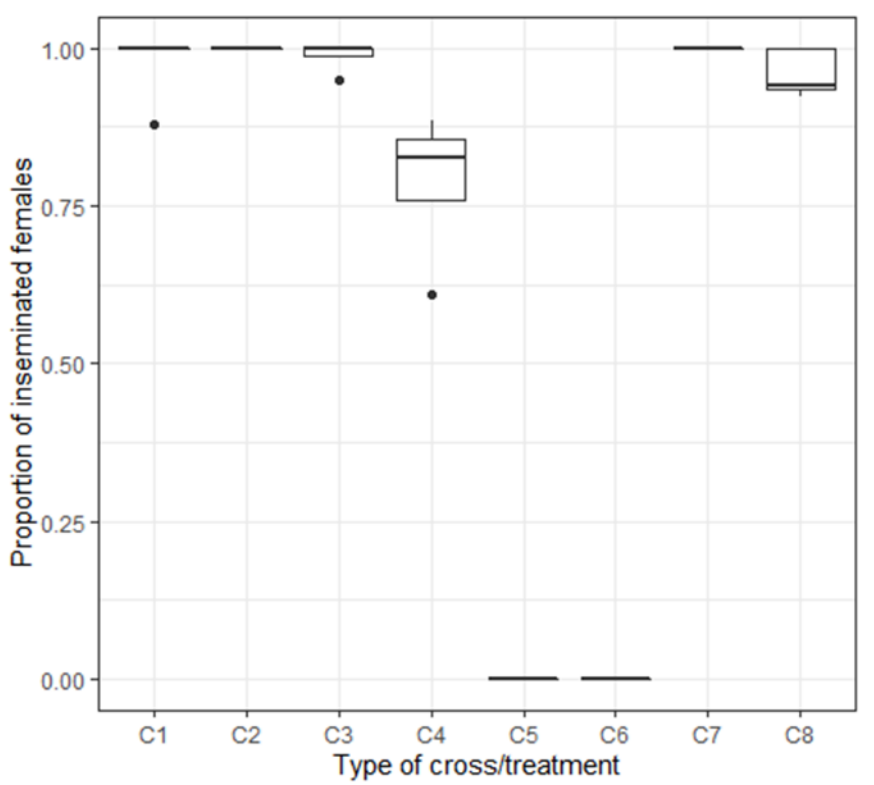

\section{Figure 3}

